REVISTA CIENCIAS BIOMÉ DICAS

ARTÍCULOS DE REVISIÓN

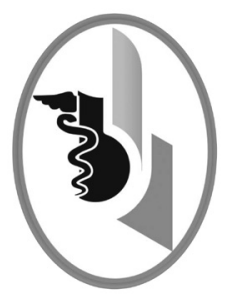

\title{
RECEPTORES CANNABINOIDES Y VÍAS DE MODULACIÓN DEL DOLOR
}

\author{
CANNABINOID RECEPTORS AND PAIN MODULATION \\ PATHWAYS
}

\author{
Castro-Barragán José ${ }^{1}$ \\ Daniels-García María ${ }^{1}$ \\ Martínez-Visbal Alfonso ${ }^{2}$ \\ Correspondencia: joca-ba@hotmail.com \\ Recibido para evaluación: septiembre-15-2015. Aceptado para publicación: marzo -12-2016.
}

\section{RESUMEN}

Introducción: los endocannabinoides son mensajeros que contienen ácido araquidónico y que se almacenan en vesículas. Los más importantes son $\mathrm{N}$-araquidoniletanolamina (anandamida) y 2-araquidonilglicerol (2-AG).

Objetivo: reconocer la importancia de los receptores cannabinoides y su papel en las vías de modulación del dolor.

Metodología: se realizó una búsqueda en PubMed, MEDLINE, Scielo, OvidSP, EBSCOhost y en las plataformas de las Revistas Lancet y New England Journal of Medicine, Anesthesiology, entre otras. Las búsquedas se limitaron a los idiomas inglés y español, así como documentos publicados entre 1990 y 2015.

Resultados: se obtuvieron 100 artículos, de los cuales se utilizaron 45 (45\%) documentos a conveniencia incluyendo artículos de revisión y artículos originales.

Conclusión: existe evidencia acerca de la presencia de receptores cannabinoides en los sitios de modulación del dolor, principalmente en la sustancia gris periacueductal (SGPA), creando dianas potenciales en el manejo del dolor crónico. Rev.cienc.biomed. 2016;7(1):93-103.

PALABRAS CLAVE

Endocannabinoides; Tetrahidrocannabinol; Modulación antigénica.

\section{SUMMARY}

Introduction: the endocannabinoids are messengers that contain arachidonic acid. They are stored in vesicles. The most important are $\mathrm{N}$-arachidonylethanolamine (anandamide) and 2-arachidonoylglycerol (2-AG).

Objective: to recognize the importance of cannabinoid receptors and their role in pain modulation pathways.

1 Estudiantes de Medicina. Pregrado. Universidad de Cartagena. Cartagena. Colombia.

2 Médico. Anestesiólogo y Algesiólogo. Profesor. Universidad de Cartagena. Universidad del Sinú. Seccional Cartagena. Cartagena. Colombia. 
Methods: a research was carried out in PubMed, MEDLINE, Scielo, OvidSP, EBSCOhost, and on the platforms of the Lancet Magazine and New England Journal of Medicine, Anesthesiology, among others. Searches were limited to English and Spanish languages, as well as documents published between 1990 and 2015.

Results: one hundred articles were obtained, of which 45 (45\%) documents were chosen by convenience including review articles and original papers.

Conclusion: there is evidence about the presence of cannabinoid receptors in pain modulation sites, mainly in the periaqueductal gray (PAGM) substance, creating potential targets in the management of chronic pain. Rev.cienc.biomed. 2016;7(1):93-103.

\section{KEYWORDS}

Endocannabinoids; Tetrahydrocannabinol; Antigenic modulation.

\section{INTRODUCCIÓN}

El sistema endocannabinoides se compone de cannabinoides endógenos (endocannabinoides), los receptores cannabinoides y las enzimas responsables de la síntesis y la degradación de los mismos (1).

Los endocannabinoides son mensajeros que contienen ácido araquidónico generado por la acción de la fosfolipasa, cuya propiedad en particular es que no suelen almacenarse en vesículas como los neurotransmisores clásicos. Los endocannabinoides más importantes identificados son $\mathrm{N}$-araquidoniletanolamina (anandamida) y 2 -araquidonilglicerol $(2-A G)(1)$.

Los endocannabinoides actúan como reguladores retrógrados de la transmisión sináptica, por tanto, después de haber sido sintetizados en las neuronas postsinápticas y puestos en libertad para actuar en los receptores cannabinoides, expresados en las neuronas presinápticas $\mathrm{y} / \mathrm{o}$ neuronas adyacentes, teniendo como resultado la atenuación de la despolarización presináptica e impidiendo la liberación de neurotransmisores (2).

Después de la síntesis y la liberación de los endocannabinoides, la señalización se termina por el proceso de recaptación, seguido por la hidrólisis intracelular de la anandamida y el 2-AG, llevada a cabo por la hidrolasa de amida de ácidos grasos (FAAH) y la lipasa monoacilglicerol (MAGL), respectivamente $(1,2)$. El objetivo de la revisión es identificar la importancia de los receptores cannabinoides y su papel en las vías de modulación del dolor.

\section{METODOLOGÍA}

Tipos de estudio: revisión temática y descriptiva en la que se incluyeron revisiones sistemáticas, investigaciones originales, editoriales, revisiones de tema, opiniones y comentarios.

Tipos de participación: documentos científicos sobre receptores cannabinoides y su papel en las vías de modulación del dolor.

Estrategia de búsqueda bibliográfica: se realizó una búsqueda en PubMed, MEDLINE, Scielo, OvidSP, EBSCOhost, y en las plataformas de las Revistas Lancet y New England Journal of Medicine, Anesthesiology, entre otras. Las búsquedas se limitaron a los idiomas inglés y español, así como documentos publicados entre 1990 y 2015.

Términos claves: fueron tomados del DeCS Y MeSH los siguientes descriptores: receptores cannabinoides, endocannabinoides, tetrahidrocannabinol, modulación del dolor, así como su respectiva traducción al inglés.

Métodos de revisión: se estudiaron títulos, resúmenes y textos completos de los documentos seleccionados en las bases de datos consideradas. Si los resúmenes se ajustaban a las exigencias del objetivo planteado, se trataban de obtener los artículos completos. Se consideraron artículos completos a conveniencia.

Recopilación y análisis de datos: se revisaron artículos completos de forma independiente. 


\section{RESULTADOS}

Se obtuvieron 100 artículos incluyendo artículos de revisión y originales, de los que se seleccionaron a conveniencia $45(45 \%)$ documentos completos para la extracción de información de acuerdo al interés de la revisión.

Receptores cannabinoides: al menos dos receptores cannabinoides diferentes se han clonado, denominados receptores CB1 y CB2 que comparten solo el $44 \%$ de homología en su secuencia de aminoácidos (3). Los receptores cannabinoides (CB1 y CB2) fueron descritos en la década de 1990 (3). Se ha descrito una variante del receptor de CB1, el $C B 1 A$, que difiere del receptor $\mathrm{CB} 1$ en su terminal amino $(3,4)$.

La localización anatómica de los receptores cannabinoides ha contribuido a la comprensión de su función fisiológica. Los receptores CB1 se expresan ampliamente en el sistema nervioso central (SNC) mientras que los receptores CB2 se expresan predominantemente en el sistema inmune, por tanto su expresión y función en el SNC sigue siendo controvertida. Dentro del sistema nervioso central, el receptor CB1 se encuentra en alta densidad y su distribución es heterogénea (5).
Los receptores CB1 y CB2 están asociados a la proteína $\mathrm{G}$ activa/inactiva (i/o), las proteínas $\mathrm{G}$ están formadas por tres subunidades alfa, beta y gamma (Figura $N^{\circ} 1$ ). Los receptores cannabinoides actúan principalmente a través de la subunidad alfa de la proteína $\mathrm{G}$ i/o generando una inhibición de la adenilciclasa que disminuyen el AMP cíclico intracelular y constituyen una señal de activación de efectos biológicos, entre ellos la regulación de la enzima fosfolipasa $C$, y asimismo la vía para generar el endocannabinoides (6). Además, los receptores CB generan una inhibición de ciertos canales de calcio dependientes de voltaje y la activación de los canales de potasio. En este sentido, la activación del receptor CB1 puede afectar la liberación de neurotransmisores mediante la modulación de calcio y conductancia de potasio (7).

Estructura de los receptores cannabinoides: los receptores CB1 y CB2 pertenecen a la superfamilia de los receptores que se acoplan al sitio de unión de proteínas G, están compuestos por una estructura que se une a la membrana a través de siete cadenas (receptores heptahelicoidales), con un dominio extracelular $\mathrm{N}$-terminal que posee sitios de glicosilación, un dominio intracelular C-terminal acoplado a un complejo de la

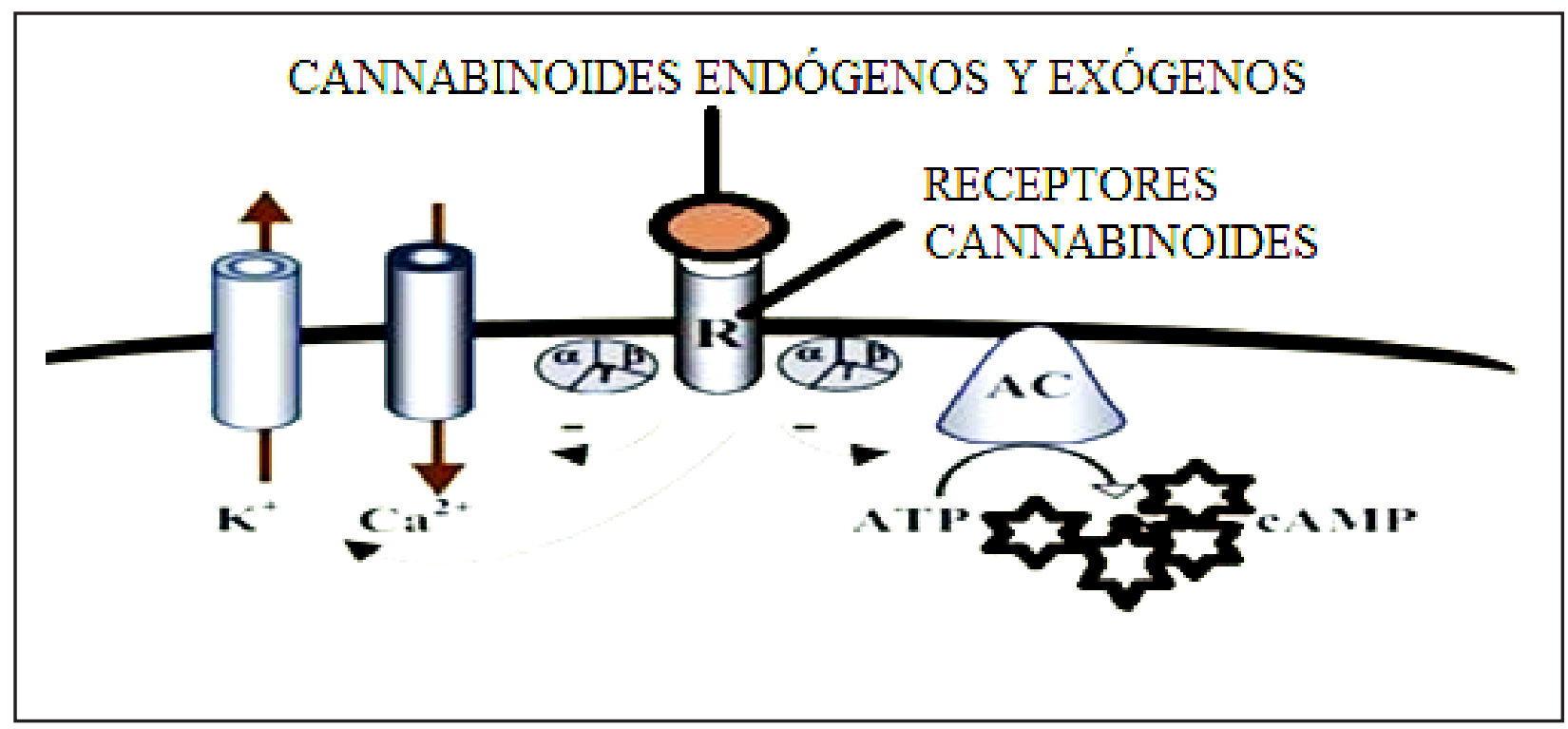

Figura No 1. Acoplamiento del receptor cannabinoide a la proteína G.

Abreviaturas: R: Receptores cannabinoides. AC: Adenil ciclisa. ATP: Adenosín trifosfato AMPc: Adenosín Monofosfato cíclico. Modificado de Díaz I. Mecanismo de transducción de señal de los cannabinoides. Sociedad Española de Investigación sobre Cannabinoides (SEIC) 2002. Pág 44-45. 


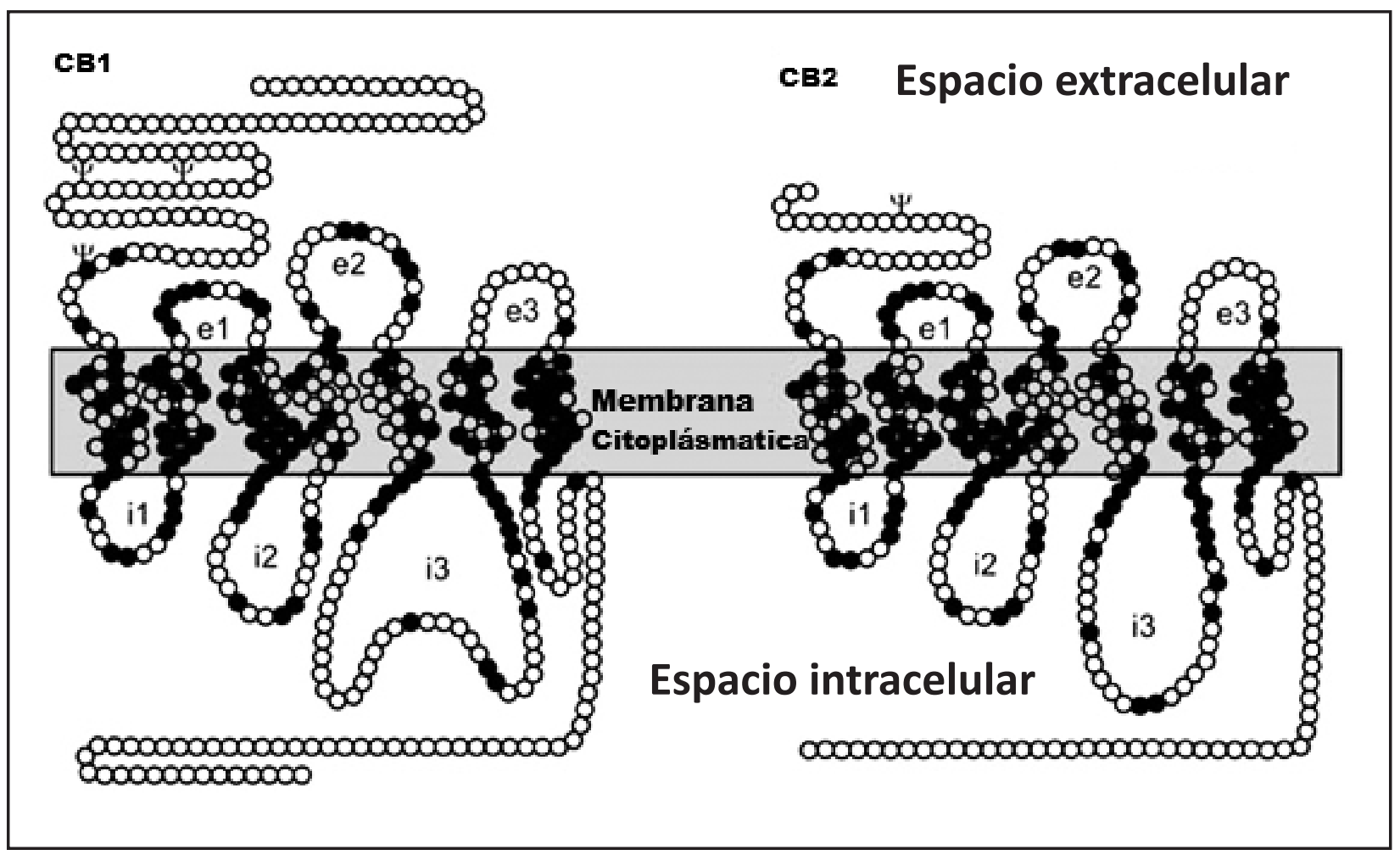

Figura No 2. Representación esquemática de los receptores CB1 y CB2. Los receptores tienen siete segmentos transmembrana. (Círculos negros) Aminoácidos comunes a los dos receptores; (círculos vacíos) aminoácidos diferentes; (y) sitios consenso de glicosilación. (e1, e2, e3) son asas extracelulares; (i1, i2, i3) son asas intracelulares. Modificado de Rodríguez U, Carrillo E. Cannabinoides: neurobiología y usos médicos. Elementos No. 60, Vol. 12, octubre - diciembre, 2005, Página 3.

proteína G y siete segmentos transmembrana hidrofóbica conectados por la alternancia de bucles extracelulares e intracelulares (Figura No 2) $(8,9)$.

Estructuralmente, el receptor CB1 es mayor que el receptor $\mathrm{CB} 2$. Las moléculas que componen los receptores son similares en cuatro de las siete regiones que se encuentran en la membrana celular (conocidas como las regiones transmembrana).

Los bucles intracelulares de los receptores cannabinoides son diferentes, lo que podría afectar la respuesta celular al ligando, puesto que estos bucles median la señalización de la proteína G -, esto es, la vía de acción principal de los receptores cannabinoides. La homología de los tipos de receptores es del $44 \%$ de la longitud total de la proteína y del $68 \%$ dentro de las siete regiones transmembrana. Los sitios de unión al ligando se definen típicamente por los bucles extracelulares y las regiones transmembrana (10).
Composición química de los receptores cannabinoides: los cannabinoides se descubrieron por primera vez en la década de 1940. Los cannabinoides son sustancias que suelen tener una estructura carbocíclica con 21 carbonos y están formados generalmente por tres anillos, ciclohexeno, tetrahidropirano y benceno (Figura No 3 ).

Los grupos de cannabinoides clásicos incluyen compuestos derivados de dibenzopirano, como son los cannabinoides derivados de la planta Cannabis sativa. La planta Cannabis sativa contiene aproximadamente 400 compuestos químicos diferentes de los que unos 60 se consideran dentro del grupo de los cannabinoides $(11,12)$. Los principales fitocannabinoides son $\Delta 9$-tetrahidrocannabinol (es el componente psicoactivo principal de la planta Cannabis sativa) ( $\triangle 9-\mathrm{THC}$ o $\mathrm{THC})$, $\Delta 8$-tetrahidrocannabinol $(\triangle 8-T H C)$, el cannabidiol (CBD) y el cannabinol (CBN), estos son hidrocarburos aromáticos $\mathrm{C} 21$ que contienen oxígeno compuestos que se encuentran en 


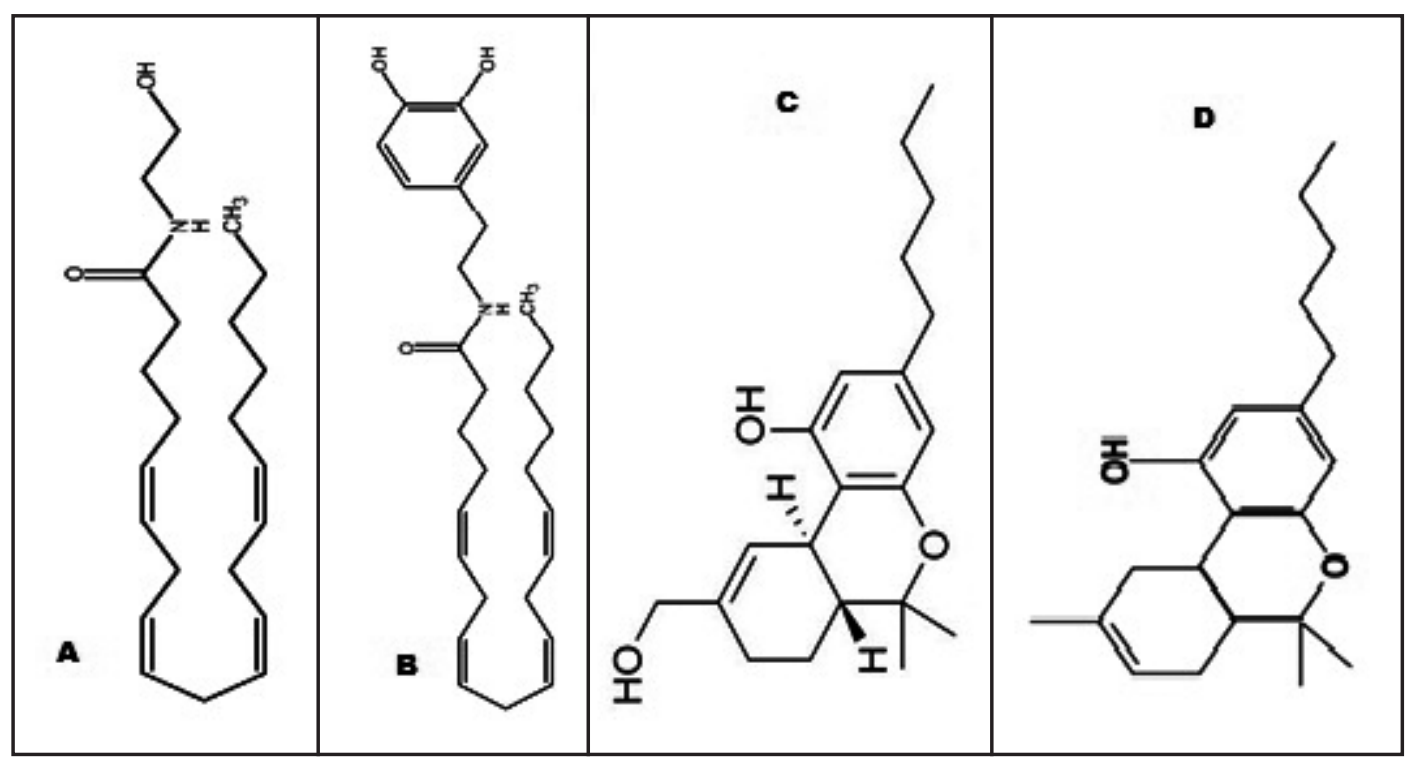

Figura No 3. Estructura química de los principales cannabinoides.

(A) Estructura química de la anandamida. (B) Estructura química del 2-araquidonoilglicerol (principales endocannabinoides). (C) Estructura química del $\Delta 9$-tetrahidrocannabinol (principal fitocannabinoide). (D) Estructura química del $\Delta 8$-tetrahidrocannabinol ( $\Delta 8-\mathrm{THC}$ ). Modificado de Guzmán, M. Galve-Roperh, I. Endocannabinoides: un nuevo sistema de comunicación en el cerebro. Farmacia. Madrid. Spain. 2010.

la planta de cannabis (13). El $\triangle 9-T H C$ es el cannabinoide con mayor potencia psicoactiva, presenta propiedades hidrofóbicas por lo que es muy soluble en lípidos $(13,14)$, esto hace que su distribución en el organismo y su eliminación presenten diferencias con lo descrito para otras drogas de abuso.

El $\triangle 8$-THC tiene un perfil farmacológico muy parecido al del $\triangle 9-T H C$, aunque sus efectos son más débiles solo aparece en algunas variedades de la planta y su concentración es muy pequeña en comparación con la del $\triangle 9$-THC $(15,16)$. Estos fitocannabinoides son capaces de estimular los receptores del sistema endocannabinoides. Con respecto al $\triangle 9$-THC, Pertwee $(17,18)$ afirma que posee una afinidad natural con los receptores CB1 y CB2, lo que en parte explica los efectos asociados a este compuesto, como por ejemplo la disminución de la actividad motora, la hipotermia, la reducción del dolor y las acciones psicoactivas del cannabis.

Por otra parte, el mismo autor afirma que, si bien el CBD posee menor afinidad con los receptores endocannabinoides, actúa indirectamente sobre ellos. Esto podría traer a su vez, grandes beneficios terapéuticos, entre los que nombra las acciones antiinflamatorias, posibles efectos anticonvulsivos, antisicóticos, ansiolíticos y antieméticos, aunque son necesarios estudios más exhaustivos. Por último, González et. al. (19) mencionan que el CBN, al tener mayor afinidad con el receptor $C B 2$ que con el $C B 1$, actúa reduciendo la actividad de la proteína quinasa $A$, lo que podría explicar el papel en la regulación inmunológica de este compuesto, ya que dicha proteína participa en la regulación de la actividad inmune.

Marihuana es el nombre popular de la hierba Cannabis sativa. El cannabis es la tercera droga más consumida en el mundo, después del alcohol y el tabaco. El cultivo, la posesión y la distribución de cannabis están regidos por normas internacionales de control de narcóticos, dado que los estados y las naciones han realizado diversas interpretaciones de estas normas. Algunos países han descriminalizado la posesión de cannabis (los Países Bajos y Portugal) y, recientemente, Uruguay y dos estados de EE. UU. (Colorado y Washington) han decidido legalizar y regular el uso del cannabis con fines recreativos (14). La vía de administración más común es la inhalación. Las hojas y flores trituradas 
de la planta Cannabis sativa se fuman (junto con los tallos y semillas) en los cigarrillos, cigarros, pipas o "blunts" (marihuana enrollada en el envolvente de tabaco de hoja de un cigarro). El hachís es un producto creado a partir de la resina de las flores de marihuana y es generalmente ahumado (por sí mismo o en una mezcla con el tabaco), pero puede ser ingerido por vía oral. La marihuana también se puede utilizar para preparar té, y su extracto a base de aceite puede ser mezclado en productos alimenticios (15).

Por otro lado, se encuentra la anandamida ( $\mathrm{N}$-araquidonoiletanolamina, AEA) y el 2-araquidonoilglicerol (2-AG) como los principales endocannabinoides $(16,20,21)$.

Localización de los receptores cannabinoides: en el SNC, el efecto analgésico de los cannabinoides está principalmente me- diado a través de los receptores CB1 situados en estructuras que median la neurotransmisión nociceptiva, incluyendo el asta dorsal de la médula, la sustancia gris periacueductal, los núcleos del rafe dorsal, la médula rostral ventromedial, la amígdala, regiones posteriores y submedius laterales del tálamo, colículo superior y el núcleo talámico ventroposterolateral (Figura No 4) (22).

Se han descrito dos niveles de acción de los cannabinoides. [A] Nivel espinal: se ha llegado a la conclusión de que los cannabinoides inhiben la actividad neuronal en el asta dorsal de la médula para producir analgesia, de tal modo que los receptores CB1 localizados en los terminales nerviosas GABAérgica inhibitorias y en las interneuronas del asta dorsal de la médula pueden ser activadas por endocannabinoides liberados en las fibras C nociceptivas, que conducen a la

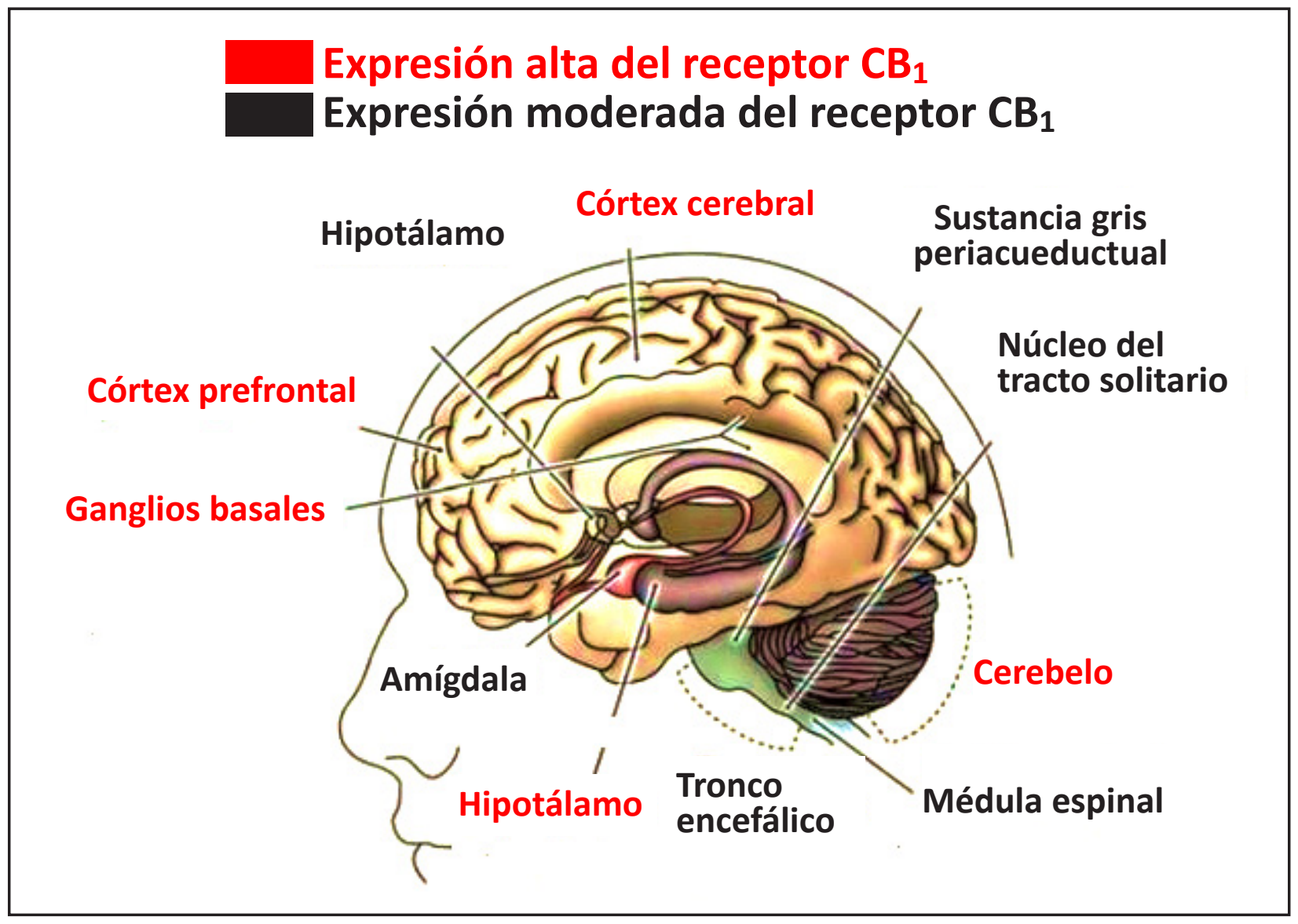

Figura No 4. Representación esquemática de las principales áreas donde se expresan los receptores CB1.

Modificado de Guzmán M., Galve Ismael. Endocannabinoides: un nuevo sistema de comunicación en el cerebro. Departamento de Bioquímica y Biología Molecular I de la Universidad Complutense de Madrid. Sociedad Española de Investigación sobre Cannabinoides (SEIC). 2012. 
inhibición de GABA y la liberación de glicina (22). [B] Nivel supra espinal: la sustancia gris periacueductal es el sitio más estudiado entre los sitios supraespinales de acción para los cannabinoides, así mismo el glutamato y GABA son dos importantes neurotransmisores que actúan a este nivel $(21,22)$.

Sin embargo, el receptor CB1 se ha encontrado recientemente en una serie de tejidos periféricos, tales como los sistemas cardiovasculares y reproductivos, así como el tracto gastrointestinal. Por otra parte, el receptor CB2 fue recientemente detectado en el sistema nervioso central (SNC), por ejemplo, en las células de la microglia (23).

Otra estructura del cerebro donde se ha demostrado el papel de los endocannabinodes es la amígdala, donde el comportamiento nociceptivo principalmente coordina el miedo y las respuestas defensivas, existiendo una alta expresión del receptor $\mathrm{CB} 1$ en el núcleo basolateral de la amígdala (BLA), una estructura que participa en la modulación nociceptiva (24).

\section{Mecanismo de acción molecular de los receptores cannabinoides: a nivel celu- lar, los receptores CB1 se localizan princi- palmente en los axones y terminales nervio- sos, y están ausentes en gran medida en el soma neuronal y dendritas. Estos hallazgos ultraestructurales sugieren una localización predominantemente presináptica de los re- ceptores CB1 (25).}

Los ligandos endógenos y exógenos ( $\Delta 9$ tetrahidrocannabinol, $\Delta 8$-tetrahidrocannabinol, anandamida y el 2-araquidonoilglicerol) se unen a los receptores CB1 que a su vez, se acoplan a la proteína $\mathrm{G}$ que activa o inhibe una serie de vías de transducción de señales. La proteína $\mathrm{G}$ inhibe directamente los canales de calcio tipo $\mathrm{N}$ y $\mathrm{P} / \mathrm{Q}$ dependientes de voltaje $\mathrm{y}$ los canales de calcio tipo A, a través de la inhibición indirecta de adenilatociclasa (26).

La activación de los receptores metabotrópicos de glutamato (mGluR) por el glutamato desencadena la activación de la fosfolipasa C (PLC), lipasa-diacylglycerol (DGL) y la vía para generar el endocannabinoides 2 -araqui- donoilglicerol (2-AG). El precursor del 2-AG es el diacilglicerol (DAG), que se forma a partir de la hidrólisis mediada por PLC en los fosfolípidos de la membrana (PIPx). EI DAG es luego hidrolizado por una enzima para generar DGL- y 2-AG. El 2-AG es liberado de la neurona postsináptica y actúa como una molécula de señalización retrógrada, activando los receptores CB1 presinápticos que residen en las terminales de las neuronas glutamatérgicas y GABAérgicas. (27-29).

La activación de receptor CB1 bloquea el flujo de calcio en el terminal presináptico, inhibiendo de este modo la liberación de los neurotransmisores (glutamato o GABA) formados en las vesícula sináptica. A continuación, los endocannabinoides se desactivan rápidamente por el transporte dentro de las células (a través de un trasportador endocannabinoides) seguido de una hidrólisis intracelular.

EL 2-AG es metabolizado por la enzima lipasa monoacilglicerol (MGL), mientras que la anandamida es metabolizada por una enzima distinta: la ácido graso amida hidrolasa (FAAH). Teniendo en cuenta que la MGL se localiza con el receptor CB1 en el terminal presináptico, mientras que la FAAH se localiza en sitios postsinápticos (Figura No 5). La existencia de un transportador endocannabinoide sigue siendo controvertida. Los inhibidores farmacológicos del sistema endocannabinoides (por ejemplo, los inhibidores de las enzimas FAAH y MGL) se han desarrollado para explotar el potencial terapéutico del sistema de señalización de los endocannabinoides en el tratamiento del dolor $(30,31)$.

Vías de modulación del dolor: la manifestación del dolor y su modulación están mediadas por las vías ascendentes y descendentes. Las neuronas en la vía del dolor ascendente reciben el aporte de fibras aferentes primarias periféricas y se proyectan desde el asta dorsal de la médula espinal a un número específico de sitios supraespinales, entre los cuales se destacan la sustancia gris periacueductal del mesencéfalo (SGPA) y la médula rostral ventromedial (MRV), que son las regiones más estudiadas y representativas que contribuyen a la modulación del dolor (Figura No 6) $(32,44,45)$. 


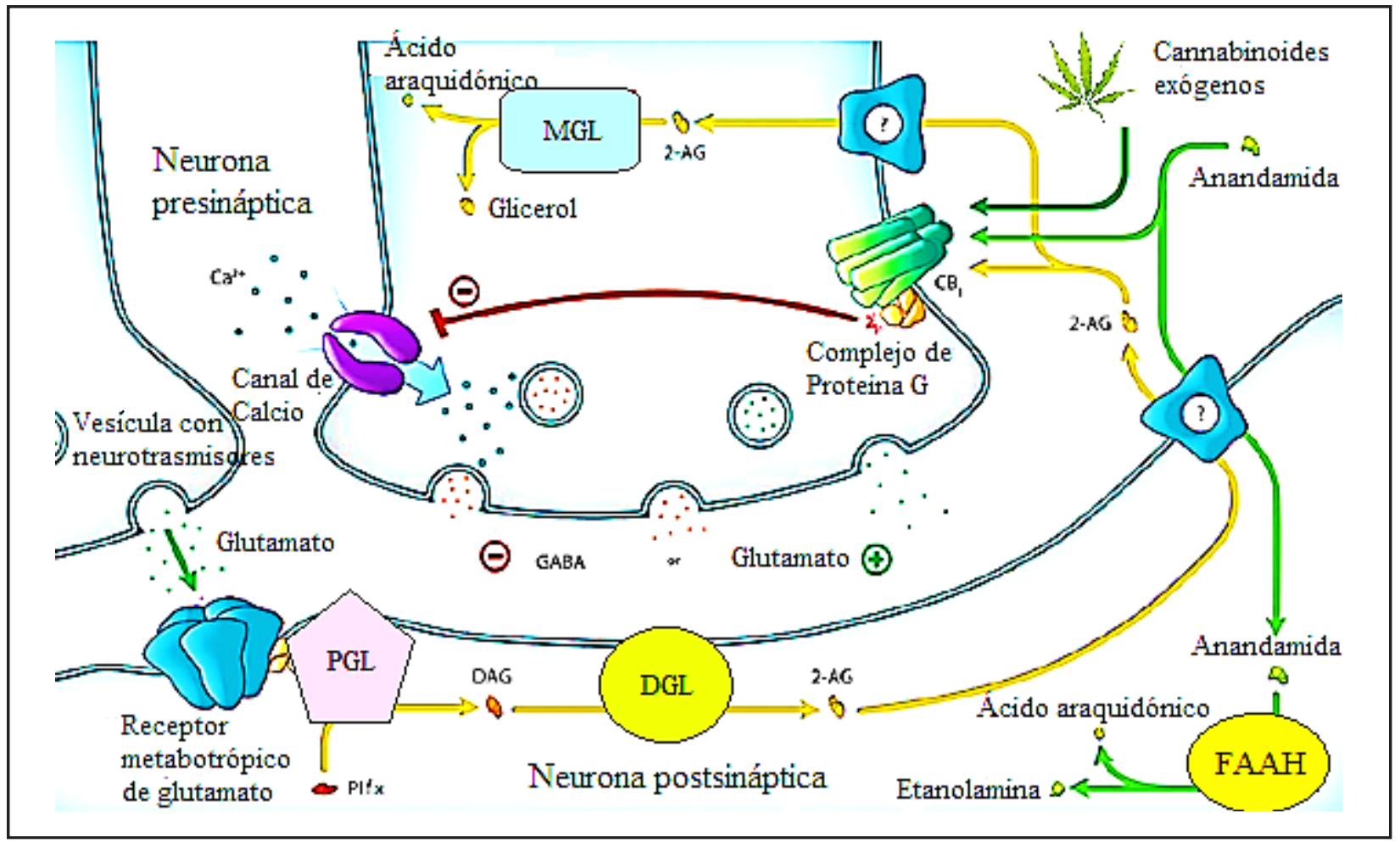

Figura No 5. Mecanismo de señalización retrógrado de los receptores cannabinoides en el sistema nervioso central. Modificado de Russo E., Hohmann A. Role of Cannabinoids in Pain Management. GW Pharmaceuticals. Pag 182. Department of Psychological and Brain Sciences, Indiana University. 2010.

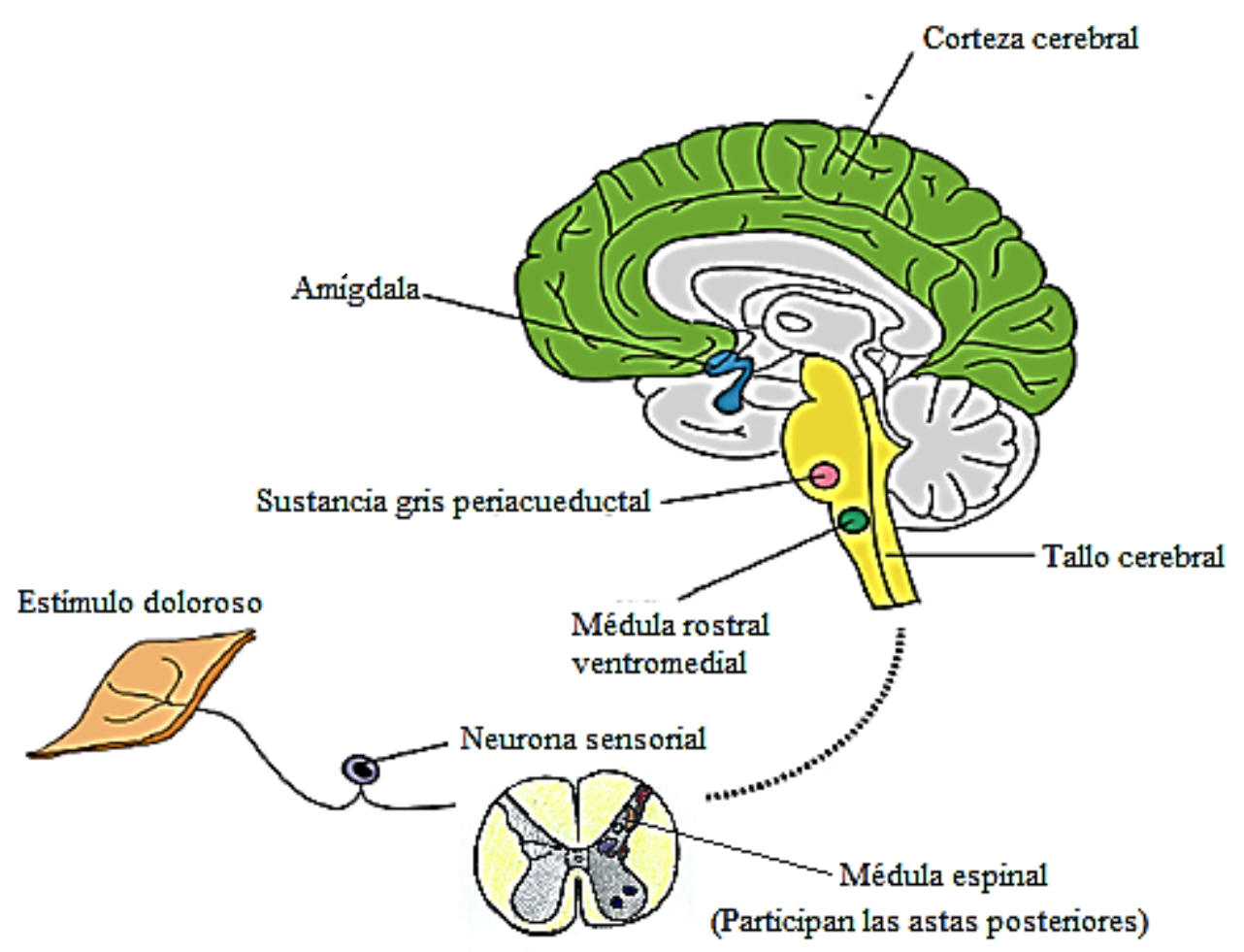

Figura No 6. Representación esquemática de las estructuras supraespinales que participan en antinocicepción mediada por cannabinoides. Modificado de Starowicz K., Malek N., Przewlocka B. Cannabinoid receptors and pain. Focus. Volume 2, May/June. 2013. 
La SGPA está interconectada con el hipotálamo y estructuras límbicas, incluyendo la amígdala, proyectándose a la MRV que a su vez, envía fibras al cuerno dorsal de la médula, encargándose de la función nociceptiva (33). La vía SGPA-MRV es reconocida como el sitio central de acción de los agentes analgésicos incluyendo los cannabinoides (34). Cuando se compara el sistema cannabinoide con el sistema opiáceo endógeno surgen similitudes y diferencias, es evidente que los mecanismos de opiáceos y cannabinoides se superponen parcialmente en lo que respecta a la anatomía, ambos están presentes en la SGPA, la médula rostral, la amígdala y el asta dorsal de la médula. Sin embargo, existe una distinción entre los sitios dentro de la SGPA que median las acciones de los cannabinoides y de los opiáceos. Hallazgos recientes han demostrado que los receptores de cannabinoides y opiáceos producen su acción en diferentes tipos de fibras periféricas (35).

La sustancia gris periacueductal es una estructura tubular organizada en cuatro regiones columnares. La activación de las columnas individuales da como resultado efectos específicos que incluyen la defensa de confrontación, escape, quietud, hipoactividad y analgesia. Las neuronas GABAérgicas y glutamatérgicas, así como los receptores CB1 que existen en la SGPA; existe evidencia funcional que corrobora la localización de los receptores CB1 en esta estructura. La médula rostroventral es un componente crítico de la vía inhibitoria descendente del dolor, la evidencia de la localización de los receptores CB1 en la MRV ha sido proporcionada por autorradiografía y por hibridación in situ, aunque la expresión de los receptores $C B 1$ en las neuronas GABAérgicas o glutamatérgicas en la MRV aún no se ha confirmado anatómicamente. Por lo tanto, los cannabinoides inhiben la transmisión sináptica GABAérgica en las neuronas de salida de la SGPA y de la MRV, y al hacerlo, se cree que producen analgesia mediante la reducción de la inhibición GABAérgica de las neuronas de salida que forman parte de una vía inhibitoria descendente del dolor $(36,37,38)$.
Funcionalmente, las neuronas de proyección glutamatérgicas envían impulsos excitatorios a la médula rostral ventromedial, las cuales son inhibidas por interneuronas GABAérgicas. De tal modo, que un aumento en la excitabilidad de las neuronas de proyección de la sustancia gris periacueductal produce analgesia a través de la activación de la médula rostral medial que envía proyecciones inhibitorias al asta dorsal de la médula. En la médula rostral medial, localizada después de la sustancia gris periacueductal en la vía descendente, se activan las células ON y OFF como respuesta antinociceptiva, del mismo modo que la administración sistémica de cannabinoides puede modular la actividad de las células ON y OFF como lo hacen los opioides, lo que sugiere que la antinocicepción inducida por cannabinoides se da a través de un mecanismo similar a la de los opioides, mediante la activación de la vía inhibitoria descendente del dolor $(39,40)$. Varios estudios han indicado que los agonistas cannabinoides aplicados en la SGPA dorsal y lateral generan analgesia, pero, la administración sistémica o directamente en la médula de un antagonista cannabinoide del receptor CB1 produce hiperalgesia (41).

Es importante destacar la existencia de un número de áreas corticales y límbicas que juegan un papel fundamental en la dimensión afectivo-motivacional del dolor. Usando la hibridación in situ y la inmunohistoquímica se ha demostrado que las células positivas para el receptor CB1 en las áreas corticales representan un pequeño porcentaje de la población total de células en cerebro de las ratas (42).

El tálamo, con sus numerosos subnúcleos, participa en la dimensión sensorial discriminatoria de dolor. Estudios han demostrado que existe expresión del receptor $\mathrm{CB} 1$ en ciertos núcleos dentro del tálamo, por ejemplo, los núcleos talámicos dorsal anterior, el núcleo habenular y el núcleo talámico reticu$\operatorname{lar}(43,44)$.

A pesar de que no ha habido ninguna evidencia directa de la localización de los receptores CB1 en las neuronas GABAérgicas en el hipotálamo. Algunos estudios han demostrado que las células neuroendocrinas 
del hipotálamo pueden liberar los endocannabinoides que luego suprimen la liberación de glutamato (45).

\section{CONCLUSIÓN}

Se han identificado dos tipos de receptores cannabinoides: los CB1 y los CB2, cada uno con una función específica. Los CB1 se han estudiado ampliamente por su mecanismo de acción como mediadores en las vías de modulación del dolor y como potenciales recursos para el tratamiento del dolor crónico, principalmente de origen neuropático. Se ha demostrado que los receptores CB2 se encuentran en regiones similares a los CB1, pero con predilección en células del sistema inmune, formando parte de la respuesta inflamatoria del organismo. El mecanismo de acción de estos receptores aún no está claro, pero se conoce que actúan a nivel presináptico en la regulación de liberación de diversos neurotransmisores presinápticos, entre ellos el glutamato. Aunque existen hallazgos significativos hacen falta estudios para determinar el papel en las vías centrales de modulación del dolor.

CONFLICTO DE INTERESES: ninguno que declarar.

FINANCIACIÓN: recursos propios de los autores.

\section{REFERENCIAS BIBLIOGRÁFICAS}

1. Freund TF, Katona I, Piomelli D. Role of endogenous cannabinoids in synaptic signaling. Physiol Rev 2003; 83:1017-66.

2. Matsuda LA, Lolait, SJ, Brownstein MJ, Young AC, Bonner TI. Structure of a cannabinoid receptor and functional expression of the cloned cDNA. Nature. 1990;346(6284):561-4.

3. Muccioli GG. Endocannabinoid biosynthesis and inactivation, from simple to complex. Drug Discov Today. 2010;15(11-12):474-83.

4. Howlett AC, Johnson MR, Melvin LS, Milne GM. Nonclassical cannabinoid analgetics inhibit adenylate cyclase: development of a cannabinoid receptor model. Mol Pharmacol. 1988;33(3):297-302.

5. Munro S, Thomas K.L, Abu-Shaar M. Molecular characterization of a peripheral receptor for cannabinoids. Nature. 1993;365(6441):61-65.

6. Díaz I. Mecanismo de transducción de señal de los cannabinoides. Sociedad Española de investigación sobre cannabinoides (SEIC) 2002.Pp 44-45.

7. Alvarez J, Palmer J. The role of endocannabinoids in pain modulation and the therapeutic potential of inhibiting their enzymatic degradation. Current pharmaceutical biotechnology. 2011;12:1644-59.

8. Howlett AC, Barth F, Bonner TI, Cabral G, Casellas P, Devane WA, Felder CC, Herkenham M, Mackie K, Martin BR, Mechoulam R, Pertwee RG. International union of pharmacology. XXVII. Classification of cannabinoid receptors. Pharmacol Rev 2002;54:161-202.

9. Hohmann, A. G, Herkenham M. Neurosci. Lett. 1998;252:13-16.

10. Rodríguez $U$, Carrillo E. Cannabinoides: neurobiología y usos médicos. Elementos. $2005 ; 12(60): 3$.

11. Farmacología de los receptores para cannabinoides; Sociedad Española de Investigación sobre Cannabinoides (SEIC) Departamento de Bioquímica y Biología Molecular Facultad de Medicina Universidad Complutense de Madrid 28040 Madrid.

12. Degenhardt L, Hall W. Extent of illicit drug use and dependence, and their contribution to the global burden of disease. Lancet 2012;379:55-70.

13. Fine P, Rosenfeld M. The Endocannabinoid System, Cannabinoids, and Pain. Rambam Maimonides Medical Journal. 2013;4:4: e0022.

14. 1Ware M, Desroches J. Cannabis medicinal y dolor. Pain: Clinical Updates. 2014;22: $1-10$.

15. Volkow N, Baler R. Adverse Health Effects of Marijuana Use. N Engl J Med 2014;370:2219-27.

16. Actualización sobre el potencial terapéutico de los cannabinoides; Sociedad Española de Investigación sobre Cannabinoides (SEIC) Departamento de Bioquímica y Biología Molecular Facultad de Medicina Universidad Complutense de Madrid 28040 Madrid.

17. Pertwee R. The diverse CB1 and CB2 receptor pharmacology of three plant cannabinoids: $\Delta$ 9-tetrahydrocannabinol, cannabidiol and $\Delta$ 9-tetrahydrocannabivarin. $\mathrm{Br} \mathrm{J}$ Pharmacol. 2008; 153(2):199-215.

18. Casadiego A, Lastra S. Cannabis sintético: aspectos toxicológicos, usos clínicos y droga de diseño. Rev. Fac. Med. 2015;63(3): 501-10.

19. González S, Sagredo O, Gómez M, Ramos JA. Química y metabolismo de los cannabinoides. En: Sociedad Española de Investigación Sobre Cannabinoides. Guía básica sobre los cannabinoides. Madrid: Universidad Complutense de Madrid; 2009. p. 13-22. 
20. Pertwee R. The diverse $\mathrm{CB} 1$ and $\mathrm{CB} 2$ receptor pharmacology of threeplant cannabinoids: $\Delta$ 9-tetrahydrocannabinol, cannabidiol and $\Delta$ 9-tetrahydrocannabivarin. $\mathrm{Br}$ J Pharmacol. 2008;153(2):199-215.

21. Fine P, Rosenfeld M. The Endocannabinoid System, Cannabinoids, and Pain. Rambam Maimonides Med J. 2013;4(4): e0022.

22. Guzmán M. Galve-Roperh I. Endocannabinoides: un nuevo sistema de comunicación en el cerebro. Farmacia.2010;11:173-79.

23. Netzahualcoyotzi, C. Muñoz, N. Martínez, I. Florán, B. Limón, D. La marihuana y el sistema endocanabinoide: de sus efectos recreativos a la terapéutica. Rev Biomed. 2009;20:128-153.

24. Whitlow, C. Freedland, C. Porrino, L. Functional consequences of the repeated administration of Delta9-tetrahydrocannabinol in the rat. Drug Alcohol Depend. 2003;71:169-77.

25. Murillo, E. Drucker, R. Endocanabinoides y su modulación en el sueño. Arch Neurocien, México. 2006:11(3): 185-93.

26. Svíženská I, Dubový P, Šulcová A. Cannabinoid receptors 1 and 2 (CB1 and CB2), their distribution, ligands and functional involvement in nervous system structures - A short review. Pharmacol Biochem Behav. 2008;90(4):501-11.

27. Abood ME, Martin BR. Molecular neurobiology of the cannabinoid receptor. International Review of Neurobiology. 1996;39:197-221.

28. Society for Neuroscience. Cannabinoids and animal physiology. 1998.

29. Palazzo E, Luongo L, Novelli V. The role of cannabinoid receptors in the descending modulation of pain. Pharmaceuticals (Basel). 2010;3(8):2661-73.

30. Bequet, F., Uzabiaga, F., Desbazeille, M., Ludwiczak, P., Maftouh, M., Picard, C., Scatton, B. \& Le Fur, G. CB1 receptor-mediated control of the release of endocannabinoids (as assessed by microdialysis coupled with LC/MS) in the rat hypothalamus. Eur. J. Neurosci. 2007;26:3458-64.

31. 18. Croci T, Manara L, Aureggi G, Guagnini F, Rinaldi-Carmona M, Maffrand JP, et al. In vitro functional evidence of neuronal cannabinoid CB1 receptors in human ileum. Br J Pharmacol 1998;125:1393-5.

32. Hasanein P, Parviz M, Keshavarz M, Javanmardi K. CB1 receptor activation in the basolateral amygdala produces antinociception in animal models of acute and tonic nociception. Clin Exp Pharmacol Physiol. 2007;34(5-6):439-49.

33. Flores. A., Maldonado R., Berrendero F. Cannabinoid-hypocretin cross-talk in the central nervous system: what we know so far. Journal Neuroscience. 2013;7:256.

34. Neubert MJ, Kincaid W, Heinricher MM. Nociceptive facilitating neurons in the rostral ventromedial medulla. Pain. 2004;110:158-165.

35. Starowicz K., Malek N., Przewlocka B. Cannabinoid receptors and pain. Focus Article.2013;2:15-20.

36. Shu-Jung Hu S. Cheng Ho Y., Chu Chiou L. No more pain upon Gq-protein-coupled receptor activation: role of endocannabinoids. European Journal of Neuroscience.2014;39: 467-84.

37. Russo E., Hohmann A. Role of cannabinoids in pain management. GW Pharmaceuticals. Ther Clin Risk Manag. 2008;4(1):245-259.

38. Mangieri RA, Piomelli D. Enhancement of endocannabinoid signaling and the pharmacotherapy of depression. Pharmacol Res. 2007;56(5):360-6.

39. Gulyas AI, Cravatt BF, Bracey MH, et al. Segregation of two endocannabinoid- hydrolyzing enzymes into pre- and postsynaptic compartments in the rat hippocampus, cerebellum and amygdala. Eur J Neurosci. 2004;20(2):441-58.

40. Neubert MJ, Kincaid W, Heinricher MM. Nociceptive facilitating neurons in the rostral ventromedial medulla. Pain. 2004;110:158-65.

41. Durnett J. Cannabinoids Modulate Pain by Multiple Mechanisms of Action. The Journal of Pain. $2000 ; 1(1): 2-14$.

42. Walker M, Huang S, Strangman N. Pain modulation by release of the endogenous cannabinoid anandamide. Rev. Psychology.1999;96(21): 14-25.

43. Rodríguez U, Carrillo E. Cannabinoides: neurobiología y usos médicos. Elementos.2005;60(12):3

44. De Novellis V, Mariani L, Palazzo E, VitaD, Marabese I, Scafuro M, Rossi F, Maione S. Periaqueductal grey CB1 cannabinoid and metabotropic glutamate subtype 5 receptors modulate changes in rostral ventromedial medulla neuronal activities induced by subcutaneous formalin in the rat. Neuroscience 2005;134: 269-281.

45. Rea K, Roche M, Finn D. Supraspinal modulation of pain by cannabinoids: the role of GABA and glutamate. British Journal of Pharmacology .2007;152:633-648. 